\title{
Imagem corporal em mulheres submetidas à cirurgia bariátrica: Interações socioculturais
}

\author{
Body image in women undergone bariatric surgery: Sociocultural \\ interactions
}

\author{
M.R. Castro, V.N. Ferreira, R.C. Chinelato, M.E. Ferreira
}

ARTIGO ORIGINAL | ORIGINAL ARTICLE

\begin{abstract}
RESUMO
Apontada como epidemia global a obesidade vem sendo tratada através da cirurgia bariátrica, método invasivo, porém, considerado o mais eficiente. Objetivou-se investigar aspectos socioculturais e seu impacto sobre a imagem corporal de mulheres submetidas à cirurgia bariátrica nos períodos pré e pós-cirúrgico. Foram entrevistadas 20 mulheres submetidas à gastroplastia há pelo menos um ano no Serviço de Controle de Hipertensão Diabetes e Obesidade (SCHDO). Os dados foram analisados sob a perspectiva qualitativa e submetidos à Análise de Conteúdo. A interação entre o contexto sociocultural e imagem corporal configurou-se nas categorias: discriminação, percepção do olhar do outro antes e após cirurgia, e percepção do próprio corpo antes e após cirurgia. Constatou-se que a imagem corporal foi elaborada a partir do meio em que viveu o grupo pesquisado. O meio externo propiciou ao sujeito sentimentos de inadequação corporal, tristeza, exclusão social e inferioridade, resultando em autoconceito negativo. Tais sentimentos foram amenizados após a cirurgia bariátrica proporcionando ao grupo autoconceito positivo decorrente de uma maior inserção social.
\end{abstract}

Palavras-chave: obesidade, corpo, saúde, mulher

ABSTRACT

Listed as a global epidemic obesity is being treated through bariatric surgery, that is a more invasive method, however, considered the most efficient. Thus, this study aimed to investigate socio-cultural aspects and their impact on body image of women who underwent bariatric surgery in pre and postsurgery periods. We interviewed 20 women who underwent gastroplasty for at least one year in the Service Control Hypertension Diabetes and Obesity (SCHDO). Data were analyzed from a qualitative perspective and submitted to Content Analysis. The interaction between body image and socio-cultural context were configured in the follow categories: discrimination, perception of other's gaze before and after surgery, and own body's perception before and after surgery. It was found that body image was drawn from the environment that the research group had lived. The external environment has provided to the subjects some feelings such as body inadequacy, sadness, social exclusion and inferiority, resulting in a negative self-concept. These feelings were minimized after bariatric surgery, providing to the group a positive self-concept, due to a greater social inclusion.

Keywords: obesity, body, health, women

Submetido: 19.07.2012 | Aceite: 13.01.2013

Marcela Rodrigues de Castro, Vanessa Nolasco Ferreira, Renata Silva de Carvalho Chinelato, Maria Elisa Caputo Ferreira. Universidade Federal de Juiz de Fora, Brasil.

Endereço para correspondência: Marcela Rodrigues de Castro, Rua 8 A, 747, ap 13, Bairro Vila Alemã, Rio Claro, São Paulo, CEP: 13506-664, Brasil.

E-mail: caputoferreira@terra.com.br 
Em relatório recente a Organização Mundial da Saúde (World Health Organization, 2012) destaca que 2.8 milhões de pessoas morrem ao ano em consequência do excesso de peso, $12 \%$ da população mundial pode ser considerada obesa, e reforça a atenção para o agravamento de doenças potencializadas pelo acúmulo de gordura como hipertensão e diabetes, além dos fatores psicossociais que atingem o obeso.

Atualmente, para o controle da obesidade estão disponíveis diversos tratamentos: dietas, programas de atividade física, medicamentos e psicoterapia. No entanto, em alguns casos, como na obesidade mórbida tais intervenções podem não surtir efeito, sendo necessária a realização da cirurgia bariátrica ou gastroplastia (Marcelino \& Patrício, 2011). Esta tem sido considerada a forma mais eficaz no emagrecimento e no controle das comorbidades de obesos mórbidos (Adams et al., 2007; Santos, Burgos, \& Silva, 2006; Segal \& Fandino, 2002) .

De acordo com Marcelino e Patrício (2011), ao primeiro ano de realizada a cirurgia bariátrica a taxa de emagrecimento chega a atingir em média de $40 \%$ a $60 \%$ do peso corporal. Assim, não é difícil imaginar que tal procedimento pode provocar mudanças significativas tanto em aspectos da saúde geral, quanto em aspectos psicossociais que envolvem sujeitos que a ela se submetem.

Candidatos à cirurgia bariátrica normalmente possuem elevados índices de depressão, humor negativo, insatisfação corporal e baixa autoestima (Carr, \& Jaffe, 2012; Kaufman, 1993; Sarwer et al., 2010). Isso é atribuído, muitas vezes, à ênfase cultural da magreza, nem sempre atingível por todos (Petroski, Pelegrini, \& Glaner, 2009) e do estigma mais duradouro da sociedade: a obesidade (Cash \& Pruzinsky, 1990; Puhl \& Heuer, 2009). O estudo de Puhl e Heuer (2009) realizado com americanos revela que pessoas obesas passam a ter uma auto crítica negativa por considerarem que a sociedade os colocam em uma categoria inaceitável.

Esse cenário vem chamando a atenção dos pesquisadores de diversas áreas para as relações existentes entre obesidade e imagem corporal. Essa é considerada a representação mental do corpo abrangendo aspectos fisiológicos, sociais, afetivos e libidinais (Schilder, 1994), e se relaciona com a experiência psicológica do sujeito sobre sua aparência e o funcionamento do seu corpo (Campana \& Tavares, 2009).

Pesquisadores (Benedetti, 2003; Santos, 2005; Castro, Carvalho, Ferreira \& Ferreira, 2010) vêm destacando o processo de construção da imagem corporal de indivíduos obesos, passando a (re) pensar o corpo não apenas sob a ótica biológica da patologia obesidade e seu tratamento, mas também enfatizando seus aspectos culturais e psicossociais. Carels et al. (2012) citam como exemplos desses aspectos a internalização de modelos corporais propostos pela mídia, o que pode gerar um descontentamento com a aparência que somados a fatores como discriminação e exclusão social pode propiciar uma autoimagem negativa.

Esta nova abordagem dada aos estudos sobre a obesidade agrega ao componente fisiopatológico outros fatores como os sentidos e significados de se ter o corpo doente, limitado e 'teoricamente' fora dos padrões vigentes (Castro et al.,2010). Além disso, tal vertente vem disponibilizando dados que podem auxiliar na recuperação e qualidade de vida desses sujeitos nos períodos pré e pós cirúrgico.

Outros estudos realizados demonstraram a articulação entre função (Castro et al.,2010), aparência (Castro, Ferreira, Braga, \& Mauerberg-deCastro, 2011) e imagem corporal sob a perspectiva intrínseca desses sujeitos, a qual se refere suas crenças, valores e sentimentos. Além desses fatores, o meio que cerca o sujeito contribui e influencia na construção da imagem corporal (Schilder, 1994). Assim, para este estudo o olhar sobre os discursos de mulheres submetidas à cirurgia bariátrica teve como objetivo investigar como o contexto sociocultural é percebido por esse público nos períodos pré e pós cirúrgico e qual impacto dessa percepção 
sobre a elaboração da imagem corporal.

\section{MÉTODO}

\section{Amostra}

A instituição pesquisada foi o Serviço de Controle de Hipertensão e Diabetes (SCHDO), pólo de obesidade do Sistema Único de Saúde que possui equipe multidisciplinar composta por cardiologista, urologista, psicólogo, enfermeiro e nutricionista. Obesos mórbidos candidatos à cirurgia bariátrica são submetidos à triagem composta de avaliações de saúde geral e psicológicas para então encaminhá-las ao procedimento cirúrgico. Do quadro de pessoas aptas à cirurgia bariátrica foram selecionadas 20 mulheres, sendo o critério de inclusão ter realizado a cirurgia bariátrica há pelo menos um ano, os critérios de exclusão foram ter tempo de cirurgia inferior a um ano e indisposição para ser entrevistada.

O tamanho da amostra foi determinado seguindo orientações de Fontanella, Ricas e Turato (2008) sobre o princípio da saturação: quando não há necessidade de incluir mais participantes, pois os resultados (na visão do pesquisador) passam a se apresentar redundantes. Tal técnica atualmente vem sendo utilizada em diferentes áreas no campo da saúde com intuito de dar fechamento amostral. Foi tomado o devido cuidado, como recomenda os autores, para que essa avaliação não fosse feita de forma acrítica e nem superficial, e, sobretudo para que tivesse pertinência teórica e articulação com o objeto estudado. Assim, trata-se de amostra não probabilística constituída em função da união das características a serem estudadas.

\section{Instrumentos}

Foi utilizada pesquisa qualitativa pela por permitir um detalhamento mais amplo e minucioso da realidade de forma complexa e contextualizada (Lüdke \& André, 1986). Foi elaborado um roteiro de entrevista semiestruturada composta por perguntas abertas e fechadas sobre dados pessoais do sujeito e a temática estudada. Para tal, foi realizado uma aproximação do campo a ser estudado por meio de observações ao longo de 6 meses no intuito de que fossem coletadas informações que auxiliassem na estruturação coerente e pertinente do instrumento. Em seguida, este foi revisado pelas pesquisadoras e submetido à avaliação de cinco juízes doutores especialistas na temática.

\section{Procedimentos e Análise Estatística}

Os discursos foram gravados, transcritos na íntegra, tratados e analisados em duas fases: qualitativa e quantitativa. Na primeira os discursos foram organizados de acordo com uma ordem temática, definida à medida que foram sendo lidos, e em sequência separados por categorias. Estas foram tratadas e analisadas a partir da Análise de Conteúdo (Bardin, 2008). Paralelo a esse trabalho foi feita contagem das falas recorrentes, sendo esta a fase quantitativa na qual foi realizada análise estatística descritiva dos dados (frequência absoluta e relativa das respostas), considerando que as respostas não eram mutuamente excludentes, podendo-se obter para uma mesma pergunta mais de uma resposta por entrevistada.

\section{RESULTADOS}

Participaram diretamente desse estudo quatro profissionais especialistas na área da imagem corporal, sendo dois psicólogos e dois educadores físicos, além de toda equipe médica (cirurgião, cardiologista, urologista), enfermagem e nutricionista do SCHDO. O grupo pesquisado apresentou o seguinte perfil: idade média de 40 anos ( \pm 7.85 ), tempo médio de realização da cirurgia de 2,85 anos $( \pm$.988). A média de peso e do IMC no período pré-operatório era de $137.1 \mathrm{Kg}( \pm 15.57)$ e $53.26 \mathrm{Kg} / \mathrm{m}^{2}$ $( \pm 6.23)$, respectivamente, sendo tais valores reduzidos para $79.41 \mathrm{Kg}( \pm 9.82)$ e $30.79 \mathrm{Kg} /$ $\mathrm{m}^{2}$ (3.74) após o procedimento. Em um ano em média as entrevistadas perderam $44.88 \%$ do peso corporal total. 
Nos discursos das colaboradoras entrevistadas constam o período da obesidade mórbida e o período após a cirurgia bariátrica. Como principal resultado destaca-se a construção da autoimagem em ambos os períodos em resposta ao meio em que se vive. Assim, a relação entre o contexto sociocultural e imagem corporal se configurou nas seguintes categorias: discriminação, percepção do olhar do outro antes e após cirurgia e percepção do próprio corpo ante e após cirurgia. Indicadores de autoimagem negativa e positiva emergiram dos discursos referentes aos períodos pré e pós cirúrgico respectivamente. A análise quantitativa simples percentual das categorias e respectivas subcategorias está expressa na Tabela 1 abaixo.

\section{DISCUSSÃO}

Foi possível verificar que aparência física e beleza afetaram as relações sociais e exerceram efeitos inter e intrapessoais no grupo pesquisado, consequentemente a imagem corporal

Tabela1

Categorias e subcategorias analisadas (n: 20 pessoas)

\begin{tabular}{ccc}
\hline Categorias/subcategorias & \multicolumn{2}{c}{ Frequência } \\
\cline { 2 - 3 } Discriminação & Relativa (\%) & Absoluta (\%) \\
\hline Ao entrar em lojas de roupas. & 8 & 40 \\
Chacotas, apelidos. & 5 & 25 \\
Empregos. & 3 & 15 \\
Recebia crítica sobre sua alimentação. & 6 & 30 \\
Foi discriminada na escola do filho. & 2 & 20
\end{tabular}

A percepção do olhar do outro antes da cirurgia bariátrica

\begin{tabular}{|c|c|c|}
\hline Não se importava. & 3 & 15 \\
\hline Olhar crítico, como se ela fosse uma aberração. & 9 & 45 \\
\hline Pena. & 3 & 15 \\
\hline Ser alegre para ser aceita. & 4 & 20 \\
\hline Rosto bonito. & 4 & 20 \\
\hline É gordo porque quer. & 2 & 10 \\
\hline Não se manifestaram & 4 & 20 \\
\hline \multicolumn{3}{|l|}{ A percepção do olhar do outro após a cirurgia bariátrica } \\
\hline Não se importa. & 1 & 5 \\
\hline Sentem-se pessoas normais. & 8 & 40 \\
\hline Liberdade para comprar qualquer roupa e ir a qualquer lugar. & 4 & 20 \\
\hline Olhares de admiração. & 8 & 40 \\
\hline Atração do sexo oposto. & 3 & 15 \\
\hline Cobrança. & 2 & 10 \\
\hline Não se manifestaram. & 3 & 15 \\
\hline \multicolumn{3}{|l|}{ A percepção do corpo antes da cirurgia bariátrica } \\
\hline Viam-se diferentes de tudo: uma aberração. & 7 & 35 \\
\hline Não se viam obesa. & 11 & 55 \\
\hline Escondiam-se atrás da gordura. & 3 & 15 \\
\hline Não se manifestaram. & 4 & 20 \\
\hline Viam-se diferentes de tudo: uma aberração. & 7 & 35 \\
\hline \multicolumn{3}{|l|}{ A percepção do corpo depois da cirurgia bariátrica } \\
\hline Sentem-se bem e bonitas. & 14 & 70 \\
\hline Não se reconheceram e ainda pensam como obesa. & 5 & 25 \\
\hline Só se sentirão bem com a cirurgia plástica. & 1 & 5 \\
\hline Não se manifestaram. & 2 & 10 \\
\hline
\end{tabular}

Fonte: coleta de dados dos autores, 2007. 
é moldada de tal forma que pode delimitar atitudes relacionadas ao corpo (Amaral, Cordás, Conti, \& Ferreira, 2011). Assim, é possível dizer que a imagem que o sujeito tem de si é criada em resposta ao meio em que o mesmo vive (Cash \& Pruzinsky, 1990), essa dinâmica aqui figurou nas entrelinhas dos discursos organizadas nas categorias discutidas abaixo.

\section{Discriminação}

Pessoas gravemente obesas são alvo de discriminação, estigmatização e preconceito em razão de sua aparência (Dixon, Dixon \& O'Brien, 2002) em diversas situações, locais, formas e pessoas. Tal fato pode ser verificado amplamente nos discursos das entrevistadas que deram destaque à discriminação por sentirem-se, por vezes, rejeitadas em função de sua obesidade mórbida, em especial em lojas de roupas, como informa a Participante 3:

"Eu sofri muito preconceito. De chegar em loja e uma vendedora virar as costas e sair pra lá e a outra virar pra mim e falar: "não tenho nada do seu tamanho [...]"

A roupa tem aqui um sentido específico de identidade entre os indivíduos, pois, sendo incorporada à imagem corporal dos sujeitos os transformam, seja positiva ou negativamente (Schilder, 1994). No entanto, pode ser fator de exclusão da mulher com obesidade mórbida.

Essa diferenciação e distanciamento de um padrão de tamanho, forma e beleza podem gerar sentimentos de tristeza e até mesmo de inferioridade como afirma a Participante 10:

"Na época da obesidade, eu não me sentia inferior no dia-a-dia, eu me sentia inferior quando acontecia um lance desses. Quando o preconceito ficava bem transparente. Nesse caso, da loja, do ônibus... Não sei se inferior, mas eu me sentia mal. Isso me fazia mal, me dava tristeza."

O relato acima demonstra que indivíduos obesos ao internalizarem esses sentimentos podem se culpar, ter alterações em seu estado de humor e sentimento negativo com relação a si próprio (Schwartz \& Brownell, 2002). Além disso, em pesquisa com o mesmo público, Marcelino e Patrício (2011) destacam elevada incidência de estados de tristeza, ansiedade e depressão devido à discriminação.

Ambientes de alimentação como restaurantes, lanchonetes e festas são apontados como locais em que o grupo foi alvo de críticas devido ao excesso de peso, destacado pela Participante 11:

"aí você vai numa festa não come de vergonha porque as pessoas olham como se você fosse acabar com tudo o que tem."

O peso social da obesidade recai sobre o indivíduo de acordo com o entendimento de obesidade de que o grupo ao qual ele pertence possui e no que ele próprio também acredita. A forma como a pessoa se vê está inundada desses aspectos sociais sobre sua aparência, papéis sociais e/ou seu comportamento (Fischler, 1995).

Comentários e chacotas pela condição da obesidade foi algo destacado nos depoimentos e atividades cotidianas e em ambientes de trabalho a exemplo da Participante 3:

"São comentários ridículos, chacotas, você não consegue passar despercebido do mundo, o mundo te olha com o olho mais gordo do que você que não tá cabendo naquela roupa. O olhar de terceiros te machuca."

Além disso, tais comentários que expressam o preconceito sobre o obeso pode se estender a toda rede de relações sociais (Benedetti, 2003) como no caso das Participantes 11 que relata a rejeição da filha na escola:

"A minha filha foi muito recriminada por minha causa na escola [...] as mães não deixam brincar com 
filho de gordo não! Com coisa que é uma doença que vai pegar... Minha filha foi muito discriminada, muito sozinha."

Os relatos expressam que o estigma da obesidade somado a discriminação, problemas de saúde e redução das possibilidades de inserção social são fatores que podem impulsionar pessoas com obesidade a realizar a gastroplastia (Marcelino \& Patrício 2011).

\section{Percepção do olhar do outro antes da cirurgia bariátrica}

A percepção do olhar do outro incidiu sobre questões relativas à aparência, pois, esta é elaborada mediante a indexação do olhar do outro, sendo de fato importante na construção e interpretação de sua própria imagem (Malysse, 2007). Isso porque, a imagem corporal compreende também a relação entre como a pessoa se vê e como ela acredita ser vista (Lovo, 2006).

Assim, o mundo externo influencia na construção da identidade e na imagem corporal da pessoa, a tal ponto que o olhar e os comentários do outro são internalizados passando a ser parte dela (Schilder, 1994). Além disso, as interações sociais são o espelho a partir do qual os indivíduos formatam atitudes, crenças ou imagens sobre si mesmos (Cash \& Fleming, 2002).

Isso é evidenciado quando as entrevistadas explanam sobre a percepção do olhar crítico onde ser obeso tornou-se algo "anormal", presente nos seguintes relatos:

"Era vista como um bicho, como diferente... muito ruim [...]porque antes a pessoa te vê colorida na rua. Com coisa que você se pintou de vermelho, roxo laranja, você está com uma melancia na cabeça."

(Participante 11)

"Eu pensava que meus pais gostavam mais dos meus irmãos do que de mim [...] nossa que enorme! Com certeza, era isso que as pessoas pensavam. Essas coisas que as pessoas pensam influenciam muito."

(Participante 1)

Fica claro que o olhar do outro é muito importante na configuração da imagem corporal, pois, esta mudará dependendo da aceitação e do julgamento que os outros fazem da imagem de seu semelhante. Há uma inter-relação na qual não se percebe o início e fim (Barros, 2001).

A penalização do outro sobre o obeso figurou nos discursos, podendo ser retratada pela fala da Participante 20:

"Aquela sensação de que todo mundo tá te olhando com aquela coisa de pena, coitadinha, novinha tão bonita e gorda, sabe, ou então, aquela coisa que eu tinha que achar que eu era abençoada porque eu era casada, por ter conseguido um marido gordo [...] se algum moço bonito passasse e olhasse pra mim, eu nunca iria achar que ele estava me achando bonita, sempre achava que estava com olhar de crítica."

Tal situação trouxe a esse grupo sentimentos de inferioridade, maior conformismo com sua situação e aceitação do mínimo que possui em sua vida, sendo talvez por isso que, na maioria dos casos, os indivíduos não faziam nada para se tratar, ou então a falência no tratamento levava logo à desistência por parte do sujeito. Kaufman (1993) interpreta tal fato como mecanismos de defesa, e mais que a mulher obesa não tem ideia de sua identidade feminina. Tais argumentos não coincidem com nossa linha de raciocínio, pois, em nossos achados ocorre o oposto: inicialmente as participantes elaboraram outra identidade que as deixasse mais confortável, e a longo prazo a cirurgia culmina pela necessidade de reduzir o peso por quererem de volta sua identidade feminina.

Nesse ínterim, frente a uma necessidade de sentirem-se integradas e aceitas pelo meio, as mulheres tentavam se mostrar alegres e simpáticas o tempo todo, mesmo que, no momento, não se sentissem assim. A Participante 16 
explica tal sensação:

"Às vezes, eu fazia coisas pra agradar os outros porque eu não queria ser aquela gorda chata, além de ser gorda eu não queria ser tachada de nada mais".

O que ocorre é que o obeso assumirá um determinado papel/personagem social, que será o preço que ele pagará para não ser rejeitado totalmente em seu meio (Fischler, 1995). Aceitar esse papel de "gordo simpático" implica em, muitas vezes, que o indivíduo seja "sacrificado em sua essência, massificado e reduzido mesmo a um elemento útil ou inútil do sistema" (Tavares, 2003). Dessa maneira, o indivíduo pode se afastar de si mesmo, de sua realidade, e suas ações passam a ser direcionadas por gratificações secundárias, que aqui significava ser inserida no contexto social.

Ainda com relação ao impacto do olhar do outro no período pré cirúrgico, um incômodo presente nas respostas versa sobre os comentários feitos apenas sobre o rosto. Este conforme Schilder (1994) possui uma importância especial por ser a parte mais expressiva do corpo: é vista por todos e possui significado psicológico por ser um dos principais meios de comunicação. O depoimento da Participante 2 confirma tal reflexão:

"Todo mundo fala: você tem um rostinho tão lindo, porque não emagrece? Todo gordo ouve isso. E a gente odeia. Porque você não é um pedaço e daqui (do pescoço pra baixo) pra lá não deu certo. Você é um conjunto."

Outro destaque a respeito da percepção do olhar do outro citado pelo grupo pesquisado trata-se da qualificação de desleixado, como no seguinte relato: "as pessoas acham que a gente é gordo porque quer" (Participante 19), ou como melhor explica essa sensação, a Participante 20, enfatizando ainda as diferenças e exigências que a sociedade coloca entre os gêneros:

"Porque a mulher gorda parece dar a impressão de desleixo e homem gordo parece que não, parece que dá a sensação de fartura, sei lá. Por exemplo, meu marido é gordo, pesa $120 \mathrm{~kg}$, e ninguém implica, ninguém fala nada. Mas comigo era diferente, parece que o olhar de aceitação é diferente. Se você vê um homem gordo com uma mulher bonita ninguém fala nada, agora se for o contrário, as pessoas pensam: será que ele gosta dela mesmo? Como ele gosta dela gorda desse jeito?"

É comum a gordura, a flacidez ou a moleza serem tomadas como símbolos tangíveis da indisciplina, do desleixo, da preguiça, da falta de certa virtude, isto é, da falta de investimento do indivíduo em si mesmo (Goldenberg \& Ramos, 2007). Ou seja, estar acima do peso pode significar não ter responsabilidade com o seu corpo, e isso, em tempos em que a saúde e a boa forma estão em primeiro lugar, é quase que transgredir uma lei.

\section{Percepção do olhar do outro após a cirurgia bariátrica}

As situações descritas acima são modificadas após a cirurgia bariátrica, provocando nas entrevistadas novas sensações e reações ao olhar alheio que observa as mudanças sofridas em sua aparência física após sua significativa perda de peso. O grupo pesquisado aponta que o olhar antes preconceituoso passa a ser admirador: "a maioria dos olhares são de admiração: nossa você foi tão corajosa!" (Participante 1). A receptividade a esses comentários e a relação de cada sujeito com seu eu e suas sensações são alguns dos fatores que determinará o quanto esse olhar influenciará e, até mesmo, direcionará a imagem de si e suas ações.

A reação mais relatada é a de sentir-se uma pessoa normal é exemplificado aqui pelas Participantes 3 e 11 respectivamente:

"Para as pessoas desconhecidas, eu sou uma pessoa normal. Mais um rosto na multidão, por sinal um rosto muito bonito vários homens olhavam. A coisa muda completamente.

Hoje sou normal. Hoje as pessoas me olham normal. 
Hoje ninguém me olha reparando, ninguém cochicha."

O sentimento de 'normalidade' enfatizado pelas entrevistadas tem a conotação de não se destacar negativamente no meio dos demais, por isso toma aqui um sentido especial de invisibilidade, o que traz satisfação a essas mulheres, como expresso abaixo:

“A minha sensação hoje é que eu não me destaco mais no meio das pessoas, eu me sinto igual a todo mundo. Eu chego no restaurante e ninguém vai olhar pro meu prato, então a imagem que eu tenho de mimé que eu sou igual a todo mundo. Dentro da minha casa, eu não sou mais a gorda da família, eu não sou ponto de referência. Eu converso com todo mundo... Hoje as pessoas falam menos."

(Participante 20)

Deixar de ser percebida como "um monstro" (Participante 11) e passar a ser considerada "normal" demonstram como "as imagens corporais nunca estão isoladas" (Schilder, 1994). Isto é, ser belo, feio, gordo e/ou magro só é validado diante da audiência do outro, quando ao mesmo tempo se é ator e espectador, ou seja, existe uma influência mútua entre as pessoas sobre suas imagens mentais de corpos. Como consequência, afirmam Alves, Pinto, Alves, Mota e Leirós (2009) o sujeito moldará suas ações e comportamentos baseados no que se é considerado 'normal' para o seu meio. É por isso, que a imagem corporal é elaborada de acordo com necessidades e tendências, no entanto, sofre alterações de acordo com o estado emocional do indivíduo (Schilder, 1994).

A mudança na aparência física provoca reajustes na dinâmica supracitada. Estar com o corpo "socialmente" aceitável aparece nos discursos juntamente com o surgimento do sentimento de liberdade para ir onde e quando elas quiserem, além de usarem qualquer tipo de roupa sem serem recriminadas, exposto pela Participante14:
"Eu uso as roupas que eu gosto, por exemplo, vermelhas, porque chama a atenção, porque não? A gente perde aquele medo de entrar numa loja e ter comentário."

Assim, pode-se inferir que quebrar as amarras da estigmatização pode significar a redução da distância social. Um exemplo disso é a atração pelo sexo oposto destacado pelas participantes 12 e 10, respectivamente: "Hoje eu sou mais paquerada do que antigamente. Com 50 anos, eu sou mais paquerada!" e "Agora, quando eu passo, os homens já mexem!" tais relatos demonstram que estar bem com o seu corpo faz com que esses sujeitos consigam se perceber, sendo, inclusive, desejados sexualmente.

Destacam-se, também, as falas divergentes, ou seja, apesar do sentimento de liberdade após a cirurgia bariátrica ser expresso na maioria dos relatos, no discurso da Participante 16, a cobrança do olhar do outro ainda a incomoda profundamente, representando aqui do seguinte modo:

"Eu estou vivendo uma cobrança muito grande. Porque a gente opera e as pessoas pensam: nossa, ela está comendo! [...] Você é muito observado sim. Mas eu acho que, em geral, o gordo é muito observado. Quando a gente é gorda, o povo olha pra ver o quanto a gente come. Agora, quando a gente emagrece, observa pra ver se não está comendo além. Cuidado: a cobrança continua!"

Tal sentimento de cobrança constante pode advir das experiências corporais iniciais e se estende para a forma de lidar com o próprio corpo e com o meio externo. Desse modo, os mecanismos de defesa utilizados a priori são internalizados e (re) utilizados inconscientemente mesmo que não haja mais necessidade deles (Pruzinsky \& Cash, 1990).

\section{Percepção do próprio corpo antes da cirurgia bariátrica}

Similarmente a outros estudos, como o de 
Yokokura et al. (2011), as participantes não se percebiam obesas ou isso ocorria apenas diante do olhar de outra pessoa e do espelho, foi relatado em mais da metade dos discursos:

"A gente se vê muito obesa quando os outros olham muito, ai você assusta, ou quando você olha no espelho, se você não tiver perante um espelho e estiver feliz, você não vê que você está obeso, você vê o seu ser, se você tiver uma vida tranquila e feliz, você não se vê obesa."

(Participante 5)

"Todo mundo falava que eu estava muito gorda, mas eu não me via gorda, eu me via grávida, eu achava assim: minha filha nasceu no outro mês eu já estaria magra, eu não achava que continuaria gorda."

(Participante 20)

Existe aí uma rejeição, mesmo que inconsciente, ao corpo real do indivíduo, por motivos diversos. Em algumas ocasiões, quando ocorre qualquer incapacidade ou deformidade, há no sujeito uma necessidade de camuflar isso. Ou seja, podemos querer esquecer um defeito, e até desejar suprimir a ideia de que estamos incapacitados, mas a consciência atormentada pela existência do mesmo estará sempre emergindo (Schilder, 1994).

Ao rejeitar sua realidade corpórea, o obeso, muitas vezes, distancia-se de seu eu corporal, o que pode significar uma forma de proteção de suas limitações internas (Tavares, 2003). Importa ressaltar que o enfrentamento de estar morbidamente ou patologicamente obeso, provocou, nessas mulheres, o olhar sobre si como algo diferente de tudo, uma aberração, como destacado a seguir:

"É quando você começa a olhar à sua volta e você percebe que o mundo todo tem outro parâmetro, outro padrão, e você está fora dele."

(Participante 3)

"Eu me via um monstro, não saía pra lugar nenhum. Evitava o máximo de sair para os lugares, não levava minha filha em teatro, cinema, nesses lugares quem levava era meu marido."

(Participante 11)

Notou-se que a condição física do sujeito obeso e suas consequentes avaliações sociais negativas repercutem no desenvolvimento de um autoconceito também negativo (Benedetti, 2003). Talvez por isso uma forma de defesa tenha sido se esconder atrás da gordura, ou se imaginando com outro corpo, como contam as Participantes 17 e 10, respectivamente: " $\mathrm{Eu}$ me tranquei no meu mundinho, não tinha vida social" e "Imaginava assim que eu era como estou agora, era como se eu não fosse gorda, como se eu tivesse outro corpo. Eu me via em outro corpo".

A cirurgia bariátrica, no público pesquisado, parece ter sido um "divisor de águas" tanto nos aspectos sociais quanto com o próprio corpo. Justamente por isso, Cash e Strachan (2002) recomendam a promoção da aceitação da realidade corporal juntamente ao tratamento da obesidade. Além disso, Marcelino e Patrício (2011) alertam que a ideia da transformação 'milagrosa' de uma pessoa obesa mórbida a pessoa sadia deve ser evitada, pois, a maioria continua convivendo com problemas limitantes, tanto no aspecto funcional, como artroses, excesso de pele, por exemplo, quanto de ordem psicológica ainda resquícios de seu histórico de obesidade.

\section{Percepção do próprio corpo após a cirurgia bariátrica}

No período pós-cirúrgico, conceitos, emoções e comportamentos apresentam-se alterados, pois, as pesquisadas relataram se sentir felizes e bonitas, como observado nos depoimentos das Participantes 10 e 6, respectivamente:

"Eu não me vejo uma pessoa diferente em tudo. A minha essência não mudou... Mas meu corpo, meu comportamento sim" e "Estou bem! Maravilhosa! 
Tudo que eu coloco fica bom: saia, blusa, vestidinho. Então estou ótima! Tem gente que se ainda se vê como obesa, eu não me vejo."

Apesar disso, em um primeiro momento não se reconheceram no pós-cirúrgico como esclarece a Participante 3:

"A minha alma não foi operada, a minha alma é gordíssima. A coisa mais simpática, à medida que eu fui emagrecendo, andando no centro da cidade, eu passava em frente às portas de banco, olhava $e$ pensava: quem é essa? Já tiveram vezes de eu voltar pra ver se era eu mesma. Não me reconhecia. Eu ainda tenho essa sensação. No principio, já tinha emagrecido 40 quilos e eu caía da cama à noite, porque eu fazia uma força pra virar e, como eu tinha muito menos, eu caía da cama."

Isso pode ocorrer porque a mudança na estrutura corporal nem sempre é seguida, imediatamente, por uma modificação da imagem corporal, podendo inclusive, segundo Steffen et al. (2012) gerar consequências negativas. A acomodação psicológica é mais fácil quando a mudança física ocorre de forma amena e não brusca, como no caso da cirurgia bariátrica. Ou seja, o indivíduo que perdeu grandes quantidades de peso de forma acelerada retém em si uma imagem de obeso. Tal imagem desaparecerá à medida que a perda de peso vai sendo elaborada com o tempo (Pruzinsky \& Edgerdon, 1990).

Em certos casos, os sujeitos relataram oscilar a imagem que têm de si, vendo-se ora magros, ora obesos, expresso através do relato da Participante 1: "Me dá uma insegurança, às vezes, eu me pego com pensamento da Alice (nome fictício) de antes... Com pensamento negativo, eu já falo: sai de mim, esse espírito é muito gordo pra caber em mim!" e enfatizado pela Participante 8:

“Então, tem hora que eu ainda me pego assim: obesa. Eu me sinto não sei como... ah! Eu não sei! Tem gente que diz que a gente muda muito. Mas do mesmo jeito que eu não me sentia engordando daquele jeito, eu ainda não senti esse emagrecimento todo. [...] A gente se vê no espelho, vê nas roupas, mas você fala: meu Deus! Se sente bem pra andar, mas parece que fica aquilo guardado na memória. Eu não sei te explicar direito. Mas eu vou, às vezes, numa loja, aí fico assim: ah! [...] a gente que é gorda não tem nada que serve!"

Ao mudar as dimensões corporais, é fato que muitas circunstâncias também mudam na vida de um indivíduo, suas aptidões, sua forma de relacionar com o mundo e consigo. No entanto, ter um corpo magro não é garantia de que essas relações sejam qualitativamente melhores. Dessa forma, o bem-estar psicossocial dependerá da capacidade do sujeito lidar com a nova situação (Benedetti, 2003).

Partindo-se dessa reflexão, pode-se inferir que o emagrecimento não implica necessariamente e naturalmente em uma imagem corporal positiva. Parece haver uma exigência sobre a capacidade de mudança e adaptação à nova situação que não pode ser esperada de forma igual para todas as mulheres. Percebeu-se, por exemplo, na fala da Participante 5, em que ela afirma que só ficará bem após a realização de cirurgias plásticas: "o corpo tá muito feio, não dá pra admirar nada não, só depois, acho que da plástica, pelo menos abdome e seios, braço e perna".

Essa preocupação com a forma corporal provocada pelo excesso de pele após emagrecimento excessivo é pontuada nos estudos de Steffen et al. (2012), Marcelino e Patrício (2011), Sarwer, Dilks e Spitzer (2011), Palmeira et al. (2010) e Sarwer et al. (2010) nos quais os autores ao encontrar dados similares, destacam que o desejo pelo cirurgia plástica pode indicar uma imagem corporal negativa possivelmente carregada dos aspectos de insatisfação e distorção da percepção do 'corpo emagrecido'.

Em outro extremo, a cirurgia bariátrica trouxe satisfação e um significado descrito como um 'nascer de novo' também encon- 
trado por Yokokura et al.(2011) em estudo com o mesmo público, e aqui expressando-se do seguinte modo: "eu acho que eu nasci de novo, que eu sou uma nova pessoa. Aquela Taís (nome fictício) obesa, deprimida, com pressão alta ficou para trás".

Embora a cirurgia bariátrica promova mudanças na imagem corporal por alterar significativamente formas corporais, Sawer et al. (2011) destacam que outros métodos de emagrecimento como dieta, tratamento medicamentoso, atividade física, terapia cognitivo-comportamental podem promover benefícios a pessoas obesas. No entanto, em seus estudos os autores ponderam sobre o fato que tais estratégias de perda de peso não são eficientes na obesidade extrema, inicialmente por reduzirem pouco o peso e segundo por não garantirem por longos períodos a manutenção dessa perda.

Ademais, ao falar de mudanças corporais, não se deve subestimar a importância da beleza e feiúra na vida das pessoas, pois, são elementos que não contam apenas para a imagem que o sujeito tem de si, mas para a imagem que os outros constroem a seu respeito e que é tomada por ele de volta. Não sendo, portanto, componentes isolados e sim fenômenos sociais de maior importância e integradores da imagem corporal (Schilder, 1994). Dessa forma, a beleza pode se tornar o caminho para a satisfação do sujeito e a feiúra o oposto.

Os depoimentos demonstraram que uma nova realidade foi criada à qual os antigos costumes, crenças e valores já não serviam mais. O corpo obeso foi transformado em corpo magro, em curto espaço de tempo, necessitando de uma adaptação interna a essa nova realidade, adaptação esta que se configurou aqui pela estreita relação entre a redução de peso e alterações na autoestima, insatisfação corporal, depressão e humor. Esses achados corroboram com as pesquisas de Palmeira et al. (2010) e Sarwer et al. (2010) nas quais os autores ainda reforçam que indivíduos que possuem melhoras nesses aspectos psicológicos não só alcançam uma adaptação corporal melhor, mas também tendem a manter a redução de peso por questões motivacionais.

Como fator limitante da pesquisa destaca-se a necessidade de ampliação da amostra e elaboração de instrumentos de avaliação específicos para essa população afim de que sejam possíveis generalizações. Além disso, se por um lado os questionários e as entrevistas permitem avaliar as influências sócio-culturais no comportamento, por outro, podem ser questionadas por sua subjetividade, sendo esta a maior limitação da metodologia escolhida para o estudo. No entanto, isso é contornado pela fidedignidade e validade das falas das entrevistadas e por terem sido os autores atentos às devidas precauções éticas e metodológicas ao utilizar esta ferramenta, e considerar este estudo de caráter qualitativo exploratório o primeiro passo para construção de ferramenta específica para avaliar imagem corporal nesse grupo específico.

\section{CONCLUSÕES}

Diante dos dados obtidos foi possível notar que a relação do sujeito com o meio em que vive constitui elemento fundamental na construção da imagem corporal para o grupo de mulheres obesas submetidas à cirurgia bariátrica. A internalização de sentimentos como tristeza, inferioridade e inadequação ao padrão corporal vigente trouxe como consequência impacto negativo na imagem corporal das entrevistadas, interferindo por vezes em seu comportamento e afastando-as de sua realidade interna. O emagrecimento após a gastroplastia proporcionou às entrevistadas uma melhor inserção na sociedade - por não se destacar negativamente - resultando em maior liberdade em suas ações, e um autoconceito positivo, o que as direcionou para uma restituição de sua identidade corporal.

Fica evidente a relevância da avaliação da imagem corporal em intervenções de saúde, em especial aquelas em que há mudanças bruscas na aparência. É preciso assim, refinar o entendimento de tal constructo no contexto 
médico, com o objetivo de identificar quais sujeitos sofrem, ou não, impacto em sua imagem corporal como reação ao tratamento, pois não necessariamente todos os pacientes terão uma mesma resposta. Desse modo, intervir na problemática da obesidade, em especial no pós-cirúrgico, é marcante e pode significar um salto qualitativo no tratamento de muitas outras pessoas que se submeterão a tal procedimento.

\section{Agradecimentos:}

Nada declarado.

\section{Conflito de Interesses:}

Nada declarado.

\section{Financiamento:}

O trabalho cuja referência completa é Imagem Corporal, autoestima e vaidade sob a perspectiva de pacientes submetidos à cirurgia bariátrica foi financiado pela Fundação de Amparo à Pesquisa do Estado de Minas Gerais - FAPEMIG, na forma de bolsa de estudo de mestrado.

\section{REFERÊNCIAS}

Adams, T.D., Gress, R.E., Smith, S.C., Halverson, R.C., Simper, S.C., Rosamond, W.D.,... Hunt, S.T. (2007). Long-Term Mortality after Gastric Bypass Surgery. New England Journal of Medicine, 357(8), 753-61.

Alves, D., Pinto, M., Alves, S., Mota, A. ,\& Leirós, V. (2009). Cultura e imagem corporal. Revista Motricidade, 5(1), 1-20. doi: 10.6063/motricidade.5(1). 184

Amaral, A.C.S., Cordás T.A., Conti M.A. ,\& Ferreira, M.E.C. (2011). Equivalência semântica e avaliação da consistência interna da versão em português do Sociocultural Attitudes Towards Appearance Questionnaire-3 (SATAQ-3). Cadernos de Saúde Pública, 27(8), 1487-1497. doi: 10.1590/S0102-311X2011000800004.

Arasaki, C.H. (2005). Cirurgia Bariátrica para tratamento da obesidade. In A.M., Claudino, ,\& M.T., Zanella (Eds.), Guia de transtornos alimentares e obesidade (2 $2^{\mathrm{a}}$ ed., pp. 287-296). São Paulo,
SP: Manole Barueri.

Bardin L. (2008). Análise de conteúdo ( $1^{\mathrm{a}}$ ed.). Lisboa, Distrito de Lisboa: Lisboa Edições.

Barros, D.D. (2001). Estudo da imagem corporal da mulher: corpo (ir) real $x$ corpo ideal. Dissertação de Mestrado, Programa de Pós-graduação em Educação Física, Universidade Estadual de Campinas, Campinas, Brasil.

Benedetti, C. (2009). De obeso a magro: a trajetória psicológica ( $1^{\mathrm{a}}$ ed.). São Paulo, SP: Vetor.

Campana A.N.N.B. ,\& Tavares M.C.G.C.F. (2009). Avaliação da imagem corporal: instrumentos e diretrizes para pesquisa. ( $1^{\circ}$ ed.). São Paulo, SP: Phorte Editora.

Carels, R.A., Burmeister, J., Oehlhlf, M.W., Hinman N., Leroy M., Bannon, E., ... Ashrafloun, L. (2012). Internalized weight bias: ratings of the self, normal weight, and obese individuals and psychological maladjustment. Journal of Behavioral Medicine. 35(1). doi: 10.1007/s10865-0129402-8.

Carr, D. ,\& Jaffe, K., The psychological consequences of weight change trajectories: Evidence from quantitative and qualitative data. (2012). Economics and Human Biology. doi: /10.1016/j. ehb.2012.04.007.

Cash, T.F. ,\& Fleming, E.C. (2002). Body image and social relations. In T.F. Cash, \& T. Pruzinsky (Eds.), Body image: a handbook of theory, research, and clinical practice ( $1^{\mathrm{a}}$ ed., pp. 277-286). New York, NY: Guilford Press.

Cash, T.F. ,\& Pruzinsky, T. (1990). Body Image: development, deviance and change ( $1^{\mathrm{a}}$ ed.). New York, NY: Guilford Press.

Cash, TF ,\& Strachan MD. (2002) .Cognitive-behavioral approaches to changing body image. In T.F. Cash, ,\& T. Pruzinsky (Eds.), Body image: a handbook of theory, research, and clinical practice (1 $1^{\text {a }}$ ed., pp. 478-486). New York, NY: Guilford Press.

Castro, M.R., Ferreira, V.N., Carvalho, R.S. ,\& Ferreira, M.E.C. (2010). Função e imagem corporal: uma análise a partir do discurso de mulheres submetidas à cirurgia bariátrica. Revista Brasileira de Ciências do Esporte, 
$32(2-4), \quad 167-183 . \quad$ doi:10.1590/S010132892010000200012.

Castro, M.R., Ferreira, M.E., Braga, G. ,\& Mauerberg-deCastro, E. (2011). Relação entre aparência e imagem corporal em pacientes submetidas à cirurgia bariátrica. Revista Motriz, 17(Supl.1), S162.

Dixon, J.B., Dixon, M.E. ,\& O’Brien, P.E. (2002). Body Image: Appearance Orientation and Evaluation in the Severely Obese. Changes with weight loss. Obesity Surgery, 12(1), 65-71. doi: 10.1381/096089202321144612.

Fischler, C. (1995). Obeso benigno, obeso maligno. In D.B., Sant'ana, (Eds.), Políticas do Corpo (1 ${ }^{\mathrm{a}}$ ed. pp. 69-80) São Paulo, SP: Estação Liberdade.

Fontanella, B.J.B., Ricas, J. ,\& Turato, E.R. (2008). Amostragem por saturação em pesquisas qualitativas em saúde: contribuições teóricas. Cadernos de Saúde Pública, 24(1), 17-27. doi: 10.1590/S0102-311X2008000100003.

Goldenberg, M. ,\& Ramos, M.S. (2007). A civilização das formas: o corpo como valor. In M. Goldenberg, (Ed.), Nu e vestido - dez antropólogos revelam a cultura do corpo carioca (2a ed., pp. 19-40) Rio de Janeiro, RJ: Record.

Kaufman, A. (1993). Obesidade feminina e sexualidade. In A. T. Cordás (Org.), Fome de cão: Quando o medo de ficar gordo vira doença: Anorexia, bulimia, obesidade (1 ${ }^{\mathrm{a}}$ ed., pp.83-93) São Paulo: Maltese.

Lovo, T.M.A. (2006). Anosognosia: imagem corporal na hemiplegia. Dissertação de Mestrado, Programa de Pós-graduação em Educação Física, Universidade Estadual de Campinas, Campinas, Brasil.

Lüdke, M. ,\& André, M.E.D. (1986). Pesquisa em educação: abordagens qualitativas ( $1^{\mathrm{a}}$ ed.) São Paulo, SP: EPU.

Malysse, S. (2007). Em busca dos (H) alteres-ego: olhares franceses nos bastidores da corpolatria carioca. In M. Goldenberg, (Ed.), Nu e vestido dez antropólogos revelam a cultura do corpo carioca ( $2^{\circ}$ ed., pp. 79 -138) Rio de Janeiro, RJ: Record. Marcelino, L.F. ,\& Patrício, Z.M. (2011). The complexity of obesity and life after bariatric surgery: a public health issue. Ciência e Saúde Coletiva,
16(12), 4767-4776. doi: 10.1590/S141381232011001300025.

Palmeira, A.L., Branco, T.L., Martins, S.C., Minderico, C.S., Silva, M.N., Vieira, P.N., ... Teixeira, P.J. (2010). Change in body image and psychological well-being during behavioral obesity treatment: associations with weight loss and maintenance. Body Image, 7(3), 187-193. doi:10.1016/j.bodyim.2010.03.002.

Petroski, E.L., Pelegrini, A. ,\& Glaner, M.F. (2009). Insatisfação corporal em adolescentes rurais e urbanos. Revista Motricidade, 5(4), 13-25. doi: 10.6063/motricidade.5(4).167.

Pruzinsky, T. ,\& Cash, T.F. (1990). Integrative themes in body-image development, deviance, and change. In T.F. Cash, ,\& T. Pruzinsky (Eds.), Body images development, deviance, and change ( $1^{\mathrm{a}}$ ed., pp. 337-349). New York, NY: Guilford Press.

Pruzinsky, T. ,\& Edgerdon, M.T. (1990). Body image change in cosmetic plastic surgery. In T.F. Cash, ,\& T. Pruzinsky (Eds.), Body images development, deviance, and change ( ${ }^{\mathrm{a}}$ ed., pp. 217-236). New York, NY: Guilford Press.

Puhl, R. \&\& Heuer, C.A. (2009). The stigma of obesity: a review and update. Obesity, 17(5), 941-964. doi:10.1038/oby.2008.636.

Santos, E.M.C., Burgos, M.G.P.A. ,\& Silva, S.A. (2006). Perda ponderal após a cirurgia bariátrica de fobi-capella: realidade de um hospital universitário do nordeste brasileiro. Revista Brasileira de Nutrição Clínica, 3(21), 188-192.

Santos, F.C.G. (2005). Magro. E agora? Histórias de obesos mórbidos que se submeteram à cirurgia bariátrica (1 ${ }^{\mathrm{a}}$ Ed.) São Paulo, SP: Vetor.

Sarwer, D.B., Dilks, R.J. \&\& Spitzer, J.C. (2011). Weight loss and changes in body image. In T.F. Cash, ,\& L. Smolak (Eds.), Body image: a handbook of science, practice, and prevention ( $2^{\mathrm{a}}$ ed., pp. 369-377). New York, NY: Guilford Press.

Sarwer, D.B., Wadden, T.A., Moore, R.H., Eisenberg, M.H., Raper, S.E. ,\& Williams, N.N. (2010). Changes in quality of life and body image after gastric bypass surgery. Surgery for Obesity and Related Diseases, 6(6), 608-614. doi:10.1016/j. 
soard.2010.07.015

Schilder, P. (1994). A imagem do corpo: as energias construtivas da psique (2 $2^{\mathrm{a}}$ Ed.). São Paulo, SP: Martins Fontes.

Schwartz, M.B. ,\& Brownell, K.D. (2002). Obesity and body image. In T.F. Cash, ,\& T. Pruzinsky (Eds.), Body image: a handbook of theory, research, and clinical practice ( $1^{\mathrm{a}}$ ed., pp. 125-164). New York, NY: Guilford Press.

Segal, A. ,\& Fandino, J. (2002). Bariatric surgery indications and contraindications. Revista Brasileira de Psiquiatria, 24(Supl III): 68-72. doi: 10.1590/S1516-44462002000700015.

Steffen, K.J., Sarwer, D.B., Thompson, J.K., Mueller, A., Baker, A.W. ,\& Mitchell, J.E. (2012). Predictors of satisfaction with excess skin and desire for body contouring after bariatric surgery. Surgery for Obesity and Related Diseases, 8(1), 92-97. doi:10.1016/j.soard.2011.06.022.
Tavares, M.C.G.C.F. (2003). Imagem corporal: conceito e desenvolvimento ( $1^{\mathrm{a}}$ ed.). Barueri, SP: Manole.

World Health Organization. (2012). World Health Statistcs: a snapshot of global health, Geneva. [Versão em PDF]. Acesso em Julho de 2012. Recuperado em http://www.who.int/gho/en/ . Yokokura, A.V.C.P., Silva, A.A.M., Araújo, G.F., Cardoso, L.O., Barros, L.C.M.M. \& Sousa, S.M.A. (2011). Obesity and bariatric surgery from the perspective of morbidly ex-obese. Saúde em Debate, 35(90), 462-469.

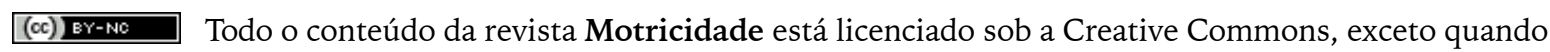
especificado em contrário e nos conteúdos retirados de outras fontes bibliográficas. 